\title{
Socioeconomic status and university students' perceptions of English as a professional language
}

\section{Elvira Barrios ${ }^{1}$, Luis Alejandro Lopez-Agudo ${ }^{2}$}

${ }^{1}$ Department of Didactic of Languages, Arts and Sports, University of Málaga, Spain, ${ }^{2}$ Department of Applied Economics (Statistics and Econometrics), University of Málaga, Spain.

\begin{abstract}
The study behind this paper aimed to assess the influence of the socioeconomic status (SES) on university students' expectations of English use in their prospective career and their perceptions of English competence as a key professional skill. The sample consisted of 109 students from two Bachelor Degree courses at the University of Málaga (Spain), one in Energy Engineering and the other one in Pedagogy. An ANOVA analysis revealed that there was no statistically significant difference between the three SES groups in the sample as to their expectations and perceptions concerning English competence. However, descriptive statistics show that the participants in the lower SES group have lower expectations regarding the role of English in their future career. Additionally, the students in this group hold a lower perception of English as a key professional skill. These findings lead us to conclude that lower SES students may be less inclined to enrol in partially or fully taught English courses at university, and that their perceptions may actually be a factor in their future career prospects in areas where English is extensively used as a lingua franca.
\end{abstract}

Keywords: English as a foreign language; socioeconomic status (SES); English Medium of Instruction (EMI); Higher Education; career prospects; perceptions. 


\section{Introduction}

In the last decades, there has been a substantial increase of English-taught programmes and courses worldwide (Dearden, 2014; Macaro et al., 2018; Wächter \& Mainworm, 2014). To illustrate, a survey of 70 European universities from 11 different countries in 2014-2015 found that $39 \%$ of them reported that they offered both individual subjects and fully Englishtaught under- and post-graduate degrees. More recently, only $7 \%$ of the surveyed universities in the study conducted by O'Dowd (2018) were not holding any English Medium Instruction (EMI) courses at all. A typical definition of EMI is this: "English-Medium instruction is when non-language courses in for instance medicine, physics or political science are taught in English, to students for whom it is a foreign language. As often as not, it is also taught by a lecturer who does not have English as a first language (L1). (Hellekjær, 2010, p. 11).

Several reasons lie behind this growth in EMI. Internationalization policies in higher education institutions, the promotion of plurilingualism and mobility by European institutions, competitiveness among universities and the need to equip the students with competences that will increase their employability are among them (Barrios \& López Gutiérrez, 2019). It is also unquestionable that English is now the lingua franca for science and that English competence is needed to access, generate and share updated scientific information.

Although research in EMI has run parallel to this growth in English-taught courses, little is yet known about the characteristics and perceptions of the potential future EMI students, and, more precisely, about how the students' SES can impinge on the perceptions concerning English as symbolic and social capital or socially recognised resource (Bourdieu, 1977) that can arguably lead to their interest in English learning and in EMI courses. One of the few studies in this area is the one conducted by Lueg und Lueg (2015), who found that the students of the lower SES in their study did not choose EMI, although they acknowledged their benefits. The authors concluded: "Lower-strata students perceive the barriers to EMI as much higher than they actually are" (p. 21). Another of their conclusions was that the tendency for students to opt for or against EMI is determined not so much by their capabilities in English, but by their conceptions. These results were partially confirmed by the study conducted by Barrios, Linde-Valenzuela and Lopez-Agudo (2020) with the same sample of students as the present study, that found that SES was not related to the students' selfconfidence in their use of English in academic situations.

Building on this argument, the present paper aims to assess the influence of the SES on university students' expectations of English use in their prospective career and their perceptions of English competence as a key professional skill, in the conviction that these perceptions may influence the students' choice of English-taught courses. 


\section{Study design}

\subsection{Participants}

A sample of 109 students from the Bachelor Degrees in Energy Engineering and Pedagogy at the University of Málaga (Spain) participated in the study. Of those, 54,1\% were males and $45,9 \%$ female. The participants were enrolled in the 1 st. year core module 'Chemistry' ( $n=60)$ or in the 3rd. year elective module 'Didactic use of media' $(n=49)$. Their ages ranged between 18 and 31 years $(M=21,25 ; S D=2,60)$. Concerning their competence in English, aproximately half (48,6\%) declared having a B1 certificate in English $(37,6 \%)$ or a higher competence certificate. Around $60 \%$ stated that they used to obtain between 'Excellent' (Sobresaliente) or 'Very good' (Notable) in English in High School (Bachillerato) and only 4 students manifested that they used to fail this subject. Around a third of the sample stated that they were not satisfied with their current level of English and $18 \%$ indicated that they did not like learning English.

\subsection{Instrument and Data Analysis}

A questionnaire was used as data gathering instrument. The first section was aimed at obtaining sociodemographic information. The second section included two scales, the 'Expectations of English use in the prospective career' scale' ( 3 items) ( $\alpha=.640)$ and the 'Perceptions of English competence as a key professional skill' (4 items) ( $\alpha=.794$ ) (Appendix I). Students rated their degree of agreement with the statements on a 6-point Likert scale between $1=$ Strongly Disagree to $6=$ Strongly Agree. This questionnaire was created on Google Forms ${ }^{\circledR}$ and completed in the first month of the period in which the modules were delivered.

A synthetic indicator of SES was constructed through a main components analysis based on: (a) the parents' highest education level, (b) the parents' highest level of occupation, (c) the numbers of books at home, and (d) the family household assets. This procedure is similar to the one used in international studies such as PISA. Three SES levels were obtained.

The data were analyzed through descriptive statistics and one-way analysis of variance (ANOVA) with Bonferroni post-test or Dunnett T3 post-test analysis performed for comparisons between multiple groups using SPSS 26 software.

\section{Results}

Table 1 shows the descriptive results obtained. As can be observed, the participants in the lower SES group (SES level 1) have lower expectations regarding the role of English in their future career. Additionally, the students in this group hold a lower perception of English as a key professional skill than the other two groups. There was not a significant effect of SES 
level on expectations regarding the role of English in the future career at the $\mathrm{p}<.05$ level for the three conditions $[F(2,106)=.706, p=.496]$. Likewise, there was not a significant effect of SES level on perception of English as a key professional skill at the $\mathrm{p}<.05$ level for the three conditions $[F(2,106)=1.860, p=.161]$.

Table 1. Descriptive results.

\begin{tabular}{lcccc}
\hline & $\begin{array}{c}\text { SES } \\
\text { level }\end{array}$ & N & Mean & Std. deviation \\
\hline & 1 & 39 & 13.33 & 3.55 \\
$\begin{array}{l}\text { Expectations of English use } \\
\text { in the prospective career }\end{array}$ & 2 & 36 & 14.00 & 2.79 \\
& 3 & 34 & 14.21 & 3.52 \\
& Total & 109 & 13.83 & 3.30 \\
Perceptions of English & 1 & 39 & 14.59 & 5.27 \\
competence as a key & 2 & 36 & 16.75 & 4.09 \\
professional skill & 3 & 34 & 16.06 & 5.43 \\
& Total & 109 & 15.76 & 5.01 \\
\hline
\end{tabular}

\section{Conclusions}

The study informing this paper tried to assess the influence of the SES on university students' expectations of English use in their prospective career and their perceptions of English competence as a key professional skill. Although no statistically significant differences have been found as to the effect of SES level on those expectations and perceptions, descriptive statistics reveal that the students in the lower SES group have both lower expectations that they will use English in ther worklife and a lower perception of English competence as a key professional skill than the other two SES groups.

These findings lead to speculate that that lower SES students may be less inclined to enrol in partially or fully taught English courses at university and that their perceptions may actually be a factor in their future career prospects in areas where English is extensively used as a lingua franca. Our results are thus in line with those obtained by Lueg und Lueg (2015) and, although more research is needed to confirm our findings, we understand that this reseach is a contribution to the much needed research into how SES factors impinge on university students' enrolment in EMI courses and on their expectations of future career prospects in areas where English competence is a requirement. 


\section{Acknowledgements}

This study stems from the Innovation Project 'Flipped classroom as an inclusive teaching strategy for bilingualism in higher education', approved and financed by the Vicerrectorado de Personal Docente e Investigador de la Universidad de Málaga for the academic years 2019-2020 and 2019-2020 (ref. PIE 19-206).

\section{References}

Barrios, E., \& López Gutiérrez, A. (2019). University teachers' perceptions at the early stages of a bilingual teacher education programme. Porta Linguarum, 32, 71-85. https://www.ugr.es/ portalin/articulos/PL_numero32/5_Elvira\%20Barrios.pdf

Barrios, E., Linde-Valenzuela, T., \& Lopez-Agudo, L. A. (2020). Percepciones de estudiantes universitarios en torno a su capacitación en inglés y motivación, in Tirant Editorial (Ed.), Técnicas y fórmulas de la nueva docencia. Valencia: Tirant Editorial.

Bourdieu, P. (1977). Outline of a theory of practice. Cambridge University Press.

Dearden, J. (2014). English as a medium of instruction - a growing global phenomenon. British Council. Retrieved from:

https://www.britishcouncil.es/sites/default/files/british_council_english_as_a_medium_ of_instruction.pdf.

Hellekjær, G. O. (2010). Lecture comprehension in English-medium higher education. Hermes Journal of Language and Communication Studies, 45, 11-34.

Lueg, K., \& Lueg, R. (2015). Why do students choose English as a medium of instruction? A Bourdieusian perspective on the study strategies of non-native English speakers. Academy of Management Learning \& Education, 14(1), 5-30. doi: 10.5465/amle.2.

Macaro, E., Curle, S., Pun, J., An, J., \& Dearden, J. (2018). A systematic review of English medium instruction in higher education. Language Teaching, 51(1), 36-76. doi: $10.1017 / \mathrm{S} 0261444817000350$.

O'Dowd, R. (2018). The training and accreditation of teachers for English medium instruction: an overview of practice in European universities International Journal of Bilingual Education and Bilingualism, 21(5), 553-563. doi:10.1080/13670050.2018.1491945.

Wächter, B., \& Maiworm, F. (Eds.) (2014). English-taught programmes in European Higher Education. Bonn: Lemmens.

\section{Appendix}

'Expectations of English use in the prospective career' scale items:

- When I think about my future job, I imagine myself using English.

- Studying English can be important to me because I think that at some point it will help me find a good job. 
- I have to study English because, if I don't, I think I will not prosper in my working career.

'Perceptions of English competence as a key professional skill' scale items:

- Not learning English would have a negative impact on my working career.

- What I want to do in my future career requires the use of English.

- It is important for me to study English because an educated person is supposed to be able to speak English.

- Studying English is important to me because I don't want to be considered an insufficiently educated person. 